\title{
TOTAL FAVORING IN PROPORTIONAL APPORTIONMENTS
}

\author{
Ion Bolun*, ORCID ID: 0000-0003-1961-7310 \\ Technical University of Moldova, Stefan cel Mare bd., 168, Chisinau, Moldova \\ *Corresponding author: Ion Bolun, ion.bolun@isa.utm.md
}

Received: 01. 28. 2021

Accepted: 02. 21. 2021

\begin{abstract}
The notion of "total favoring" of large or of small beneficiaries in proportional apportionments of entities is defined as a particular case of favoring. It is proven that the number of known conditions of total favoring of beneficiaries in an apportionment (APP) can be considerably reduced. Thus, the volume of calculations to be performed for the respective computer simulation was reduced. In order to quantitatively estimate the total favoring of beneficiaries by APP methods, three indicators were used: the percentage of apportionments, in which large beneficiaries are totally favored; the percentage of apportionments, in which small beneficiaries are totally favored; the percentage of total favoring of large or of small beneficiaries, depending on the APP method applied. A total of five APP methods are being researched: Hamilton (Hare), Sainte-Laguë (Webster), d'Hondt (Jefferson), Huntington-Hill and Adapted Sainte-Laguë. Based on results of computer simulation, the total favoring of beneficiaries by these five APP methods was estimated, including comparatively. For example, it has been identified that the d'Hondt method does not always totally favors beneficiaries to a greater extent than the Huntington-Hill method. At the same time, the Adapted Sainte-Laguë method always totally favors small beneficiaries less compared to the Huntington-Hill method.
\end{abstract}

Keywords: apportionment method, apportionment problem, comparative analysis, computer simulation, favoring of beneficiaries, quantitative estimate.

Rezumat. Este definită noțiunea de "favorizare totală" a beneficiarilor mari sau a celor mici în repartizări proporționale de entități, ca un caz particular de favorizare. Este dovedit că numărul condițiilor cunoscute de favorizare totală a beneficiarilor într-o repartizare (APP) poate fi redus considerabil. Astfel, a fost redus și volumul calculelor de efectuat pentru simularea informatică respectivă. Pentru a estima cantitativ favorizarea totală a beneficiarilor de către metodele APP, s-au folosit trei indicatori: procentajul repartizărilor, în care sunt total favorizați beneficiarii mari; procentajul repartizărilor, în care sunt total favorizați beneficiarii mici; procentajul favorizării totale a beneficiarilor mari sau a celor mici, în funcție de metoda APP aplicată. În total sunt cercetate cinci metode APP: Hamilton (Hare), Sainte-Laguë (Webster), d'Hondt (Jefferson), Huntington-Hill și Sainte-Laguë Adaptată. Pe baza rezultatelor simulării informatice, a fost estimată, inclusiv comparativ, favorizarea totală a beneficiarilor de aceste cinci metode APP. De exemplu, s-a identificat 
că nu întotdeauna metoda d'Hondt favorizează total beneficiarii într-o măsură mai mare, decât metoda Huntington-Hill. În același timp, metoda Sainte-Laguë Adaptată întotdeauna favorizează total beneficiarii mici mai puțin, comparativ cu cea Huntington-Hill.

Cuvinte cheie: analiză comparativă, estimare cantitativă, favorizarea beneficiarilor, metodă de repartizare, problemă de repartizare, simulare informatică.

\section{Introduction}

It is often necessary to distribute a given number $M$ of discrete entities of the same kind among $n$ beneficiaries, in proportion to a numerical characteristic assigned to each of them $V_{i}, \mathrm{i}=\overline{1, \mathrm{n}}$. This is known as proportional apportionment (APP) problem [1 - 3]. The integer character of this problem usually causes a certain disproportion of the apportionment $x_{i}, i=\overline{1, n} \quad[1,4-6]$, some beneficiaries being favored at the expense of others. Favoring of beneficiaries leads to the increase of disproportionality and vice versa [6]. Therefore, reducing the favoring in question is one of the basic requirements when is choosing the APP method to be applied under concrete situations (free of bias condition $[1,3])$.

As it is well known, the d'Hondt method favors large beneficiaries (with larger $V_{i}$ value) $[1,4,6]$, and Huntington-Hill method favors the small ones (with smaller $V_{i}$ value) [4, 6]. But which of the two favors beneficiaries to a larger extent? Preferences, in this sense, between methods, can help. Par example, in [7], five APP methods are placed „in the order as they are known to favor larger parties over smaller parties". However, the best way is to estimate this property quantitatively. One approach in this aim is proposed in [8]. Another, a specific one, based on the definition of (total) favoring of large or of small beneficiaries by an apportionment method done in [1], is examined in this paper. Estimates of the frequency of total favoring in apportionments for the widely used Hamilton (Hare), Sainte-Laguë (Webster), d'Hondt (Jefferson), Huntington-Hill and Adapted Sainte-Laguë methods are obtained by computer simulation.

\section{Essence of favoring of beneficiaries in apportionments}

The essence of favoring of beneficiaries in apportionments is described in different papers, including the $[4,9,10]$ ones. In $[6]$ they are distinguished three notions of favoring of beneficiaries by an APP method:

a) favoring of a beneficiary in an apportionment;

b) favoring of large or of small beneficiaries in an apportionment;

c) favoring of large or of small beneficiaries overall by an apportionment method.

It is considered that a beneficiary $i$ is favored if a larger number $x_{i}$ of entities is distributed to him than would be due according to the $V_{i}$ value, more precisely if $x_{i}>M V_{i} / V$, where $M=x_{1}+x_{2}+\ldots+x_{n}$ and $V=V_{1}+V_{2}+\ldots+V_{n}$. Of course, the lack of favoring is possible only if the equalities $\left\lfloor M V_{i} / V\right\rfloor=M V_{i} / V, i=\overline{1, n}$ take place; here $\lfloor z\rfloor$ means the integer part of the real number $z$. In practice, such equalities rarely occur and that is why some beneficiaries are favored and others, respectively, are disfavored.

In a formalized form, the first, probably, definition of favoring of large or of small beneficiaries in apportionments is done in [1].

Definition 2 (according to [1, p. 125]). An apportionment method favors large parties if 


$$
\frac{\sum_{i \in L} x_{i}}{\sum_{i \in L} V_{i}}>\frac{\sum_{j \in S} x_{j}}{\sum_{j \in S} V_{j}}
$$

and it favors small parties if

$$
\frac{\sum_{i \in L} x_{i}}{\sum_{i \in L} V_{i}}<\frac{\sum_{j \in S} x_{j}}{\sum_{j \in S} V_{j}},
$$

where $L$ and $S$ are subsets of $\{1,2, \ldots, n\}$ such that $x_{i}>x_{j}$ whenever $i \in L$ and $j \in S$ [3].

If, when applying an APP method to any of possible initial data, requirement (1) or, respectively, requirement (2) always occurs, then it can be considered that this method "overall favors" large or, respectively, small beneficiaries (parties). But there are no known such methods that would be used in practice. In such a situation the Definition 2 can be used to identify the favoring of large or of small beneficiaries in particular apportionments.

At the same time, it is considered that d'Hondt method favors large beneficiaries, in sense that more frequently it favors large beneficiaries that it favors the small ones, and Huntington-Hill method favors small beneficiaries, in sense that more frequently it favors small beneficiaries that it favors the large ones in apportionments. Moreover, in one and the same apportionment may be favored some large beneficiaries and some small beneficiaries. The approach proposed in [8] can identify, if such an apportionment favors predominantly large or predominantly small beneficiaries. That's why in this paper the apportionments compliant with requirement (1) are considered "total favoring" large beneficiaries, and the ones compliant with requirement (2) are considered "totally favoring" small beneficiaries. These are particular cases of the "favoring" of beneficiaries - large (predominantly) or small (predominantly) in sense of [8].

Finally, to determine if an APP method totally favors (overall) large beneficiaries or it totally favors (overall) small beneficiaries, it is needed to have apportionments on infinity (sufficient large number) of cases of initial data. If the frequency of total favoring of large beneficiaries is larger than the frequency of total favoring of small beneficiaries, then it is considered that the APP method totally favors (overall) large beneficiaries and vice versa.

\section{Number of restrictions to check the total favoring in apportionments}

The frequency of total favoring of large (small) beneficiaries, on a sufficient large number of cases of initial data, can be determined by computer simulation. To do this, it is important to know how many of different inequalities (1) or, in case of favoring of small beneficiaries, of the (2) ones there are.

Without diminishing the universality of the approach, below it is considered that the $n$ beneficiaries are ordered in non-ascending order of $V_{i}, i=\overline{1, n}$, that is $V_{1}>V_{2}>V_{3}>\ldots>V_{n}$. In proportional apportionments, if $V_{i}>V_{j}$ then $x_{i} \geqslant x_{j}$. Let's consider the apportionments for which $x_{1}>x_{2}>x_{3}>\ldots>x_{n}$. For such an apportionment and $|L|+|S|=n$, there are $n-1$ variants of different pairs of subsets $L$ and $S: L_{1}=\{1\}, S_{1}=\{2,3, \ldots, n\} ; L_{2}=\{1,2\}, S_{2}=\{3,4$, $\ldots, n\} ; \ldots ; L_{n-1}=\{1,2,3, \ldots, n-1\}, S_{n-1}=\{n\}$. However, if all cases, for which $|L|+|S| \leqslant n, L \neq$ $\varnothing, S \neq \varnothing$, to be taken into account, then the number $K_{n}$ of variants of different pairs of subsets $L$ and $S$ is considerably larger than $n-1$.

Statement 1. In general case, the number $K_{n}$ of variants of different pairs of subsets $L$ and $S$ of $\{1,2, \ldots, n\}$, such that $x_{i}>x_{j}$ whenever $i \in L$ and $j \in S$, is determined according to recurrent formula

$$
K_{n}=2 K_{n-1}-K_{n-2}+2^{n-1}-1, n \geqslant 2
$$


where $K_{0}=K_{1}=0$.

Indeed, one has $K_{2}=1$, because the only possible variant is $L=\{1\}$ and $S=\{2\}$. From the other hand, according to (3) takes place $K_{2}=2 \times 0-0+2^{2-1}-1=1$.

Also, $K_{3}=5$, because:

1) for $L=\{1\}$ there are three $\left(C_{2}^{1}+C_{2}^{2}=2^{2}-1\right)$ possible variants of $S$, that is $\{2\},\{3\}$ and $\{2,3\}$;

2) for $L=\{1,2\}$ there is one $\left(C_{1}^{1}\right)$ possible variant of $S$, that is $\{3\}$;

3 ) for $L=\{2\}$ there is one $\left(C_{1}^{1}\right)$ possible variant of $S$ (as for $K_{2}$ ), that is $\{3\}$.

From the other hand, according to (3) one has $K_{3}=2 \times 1-0+2^{3-1}-1=5$.

When $n=4$, takes place $K_{4}=16$, because:

1) for $L=\{1\}$ there are $7\left(C_{3}^{1}+C_{3}^{2}+C_{3}^{3}=2^{3}-1\right)$ possible variants of $S$, that is $\{2\}$, $\{3\},\{4\},\{2,3\},\{2,4\},\{3,4\}$ and $\{3,4,5\}$;

2) for $L=\{1,2\}$ there are three $\left(C_{2}^{1}+C_{2}^{2}\right)$ possible variant of $S$ (as in case (1) of $K_{3}$ ), that is $\{3\},\{4\}$ and $\{3,4\}$;

3) for $L=\{1,2,3\}$ there is one $\left(C_{1}^{1}\right)$ possible variant of $S$ (as in case (2) of $K_{3}$ ), that is $\{4\}$;

4) for $L=\{2\}$ there are three $\left(C_{2}^{1}+C_{2}^{2}\right)$ possible variants of $S$ (as in case (1) of $K_{3}$ ), that is $\{3\},\{4\}$ and $\{3,4\}$.

5) for $L=\{2,3\}$ there is one $\left(C_{1}^{1}\right)$ possible variant of $S$ (as in case (2) of $K_{3}$ ), that is $\{4\}$;

6) for $L=\{3\}$ there is one $\left(C_{1}^{1}\right)$ possible variant of $S$ (as in case (3) of $K_{3}$ ), that is $\{4\}$.

So, in cases (2)-(3) and, separately, in cases (4)-(5) of $K_{4}$, there are the same number of possible variants of $S$ as in cases (1)-(2) of $K_{3}$. Therefore one has $K_{4}=2^{3}-1+2 K_{3}-K_{2}=7$ $+2 \times 5-1=16$. The same result can be obtained also in the following way. Evidently, in cases of $K_{4}$, in which subset $L$ begins with beneficiaries from 2 to $3=n-1$, there are a summary number of possible variants of $S$ equal to $K_{3}$. Thus, the value of $K_{4}$ is larger than that of $K_{3}$ by the summary number of possible variants of $S$ for cases in which subset $L$ begins with beneficiary 1 , that is for cases of subsets $\{1\},\{1,2\}$ and $\{1,2,3\}$. For the subset $\{1\}$ of $K_{4}$, there are $2^{n-1}-1=2^{3-1}-1$ possible variants of $S$, and for subsets $\{1,2\}$ and $\{1,2$, $3\}$ of $K_{4}$ the summary number of possible variants of $S$ is equal to those for subsets $\{1\}$ and $\{1,2\}$ of $K_{3}$, that is to $K_{3}-K_{2}$.

Similarly, when $n=j$ beneficiaries:

1) for $L=\{1\}$ there are $\left(C_{j-1}^{1}+C_{j-1}^{2}+\cdots+C_{j-1}^{j-1}=2^{j-1}-1\right)$ possible variants of $S$;

2 ) in cases, in which subset $L$ begins with beneficiaries from 2 to $j-1$, there are a summary number of possible variants of $S$ equal to $K_{j-1}$;

3 ) for subsets $\{1,2\},\{1,2,3\}, \ldots,\{1,2, \ldots, j\}$ of $K_{j}$, the summary number of possible variants of subset $S$ is equal to those for subsets $\{1\},\{1,2\}, \ldots,\{1,2, \ldots, j-1\}$ of $K_{j-1}$, that is to $K_{j-1}-K_{j-2}$.

Thus, one obtains $K_{n}=2^{n-1}-1+K_{n-1}+\left(K_{n-1}-K_{n-2}\right)=2 K_{n-1}-K_{n-2}+2^{n-1}-1$.

Data of Table 1 show that $K_{n}$ value increases rapidly with the increase of $n$, becoming more than 2 mil at $n=20$ beneficiaries.

Table 1

Some values of $K_{n}$

\begin{tabular}{cccccccc}
\hline $\boldsymbol{n}$ & $\boldsymbol{K}_{\boldsymbol{n}}$ & $\boldsymbol{n}$ & $\boldsymbol{K}_{\boldsymbol{n}}$ & $\boldsymbol{n}$ & $\boldsymbol{K}_{\boldsymbol{n}}$ & $\boldsymbol{n}$ & $\boldsymbol{K}_{\boldsymbol{n}}$ \\
\hline 2 & 1 & 4 & 16 & 7 & 219 & 15 & 65399 \\
\hline 3 & 5 & 5 & 42 & 10 & 1981 & 20 & 2096920 \\
\hline
\end{tabular}


For approximate calculations, instead of recurrent formula (3) can be used the following one

$$
K_{n} \approx 2 \times 10^{3 n / 10}, n=7 \div 68,
$$

where the absolute value of the relative error doesn't exceed $15 \%$. The relative error is positive decreasing from $14.97 \%$ to $0.96 \%$ at $n=7 \div 10$ and negative decreasing from $0.66 \%$ to $-14.89 \%$ at $n=11 \div 68$.

\section{Redefining the notion of total favoring in apportionments}

The $K_{n}$ value determined according to (3) can be considerable, especially at large values of $n$. Thus, for computer simulation, it is important to reduce the number of requirements (1) and (2). A solution is done by Statement 2.

Statement 2. In case of $x_{1}>x_{2}>x_{3}>\ldots>x_{n}$, the necessary and sufficient conditions for compliance with all $K_{n}$ inequalities (1) are the $n-1$ ones

$$
\frac{x_{1}}{V_{1}}>\frac{x_{2}}{V_{2}}>\cdots>\frac{x_{n}}{V_{n}}
$$

and with all the $K_{n}$ restrictions (2) are the $n-1$ ones

$$
\frac{x_{1}}{V_{1}}<\frac{x_{2}}{V_{2}}<\cdots<\frac{x_{n}}{V_{n}} .
$$

Indeed, the necessity of conditions (4) is evident. They belong to the $K_{n}$ ones and cover all $n(n-1) / 2$ variants of pairs $\{L, S\}$ for $|L|=|S|=1$. At the same time, they establish only $n-1$ relations for the total of $n$ beneficiaries - the minimal possible number. A similar situation is with the necessity of conditions (5).

Regarding the sufficiency of inequalities (4), let's begin with proving the following inequalities

$$
\frac{x_{1}+x_{2}}{V_{1}+V_{2}}>\frac{x_{3}}{V_{3}}, \frac{x_{1}}{V_{1}}>\frac{x_{2}+x_{3}}{V_{2}+V_{3}}, \frac{x_{1}+x_{2}}{V_{1}+V_{2}}>\frac{x_{3}+x_{4}}{V_{3}+V_{4}}
$$

Because of $\frac{x_{2}}{V_{2}}>\frac{x_{3}}{V_{3}}$, for it to take place (6), it is sufficient to prove that

$$
\frac{x_{1}+x_{2}}{V_{1}+V_{2}}>\frac{x_{2}}{V_{2}}
$$

Let's consider the equality

$$
\frac{x_{1}+y}{V_{1}+V_{2}}=\frac{x_{2}}{V_{2}}
$$

From (10) one has $y=\left(x_{2} V_{1}+x_{2} V_{2}-x_{1} V_{2}\right) / V_{2}=x_{2} V_{1} / V_{2}+x_{2}-x_{1}$. If $x_{2}>y$, then based on (9), (10) and $\frac{x_{2}}{V_{2}}>\frac{x_{3}}{V_{3}}$ the inequality (9) occurs, too. So, if takes place $x_{2}>x_{2} V_{1} / V_{2}+x_{2}-x_{1}$, that is if $x_{1} / V_{1}>x_{2} / V_{2}$, then the inequality (9) occurs. But the inequality $x_{1} / V_{1}>x_{2} / V_{2}$ takes place, then (9) occurs and therefore (6) occurs, too. Evidently, based on same considerations, take place

$$
\frac{x_{i}+x_{j}}{V_{i}+V_{j}}>\frac{x_{r}}{V_{r}}, i=\overline{1, r-2}, j=\overline{l+1, r-1}, r=\overline{3, n} .
$$

Also, by induction it is easy to show that occur

$$
\frac{\sum_{i \in L} x_{i}}{\sum_{i \in L} V_{i}}>\frac{x_{r}}{V_{r}}
$$


where $L$ is any subset of $\{1,2, \ldots, j\}, j=\overline{1, r-1}$ and $r=\overline{2, n}$. Indeed, noting $x_{1,2}=x_{1}+x_{2}$ and $V_{1,2}=V_{1}+V_{2}$ (one new conventional beneficiary in place of two former ones) and based on (6) one has $x_{1,2} / V_{1,2}>x_{3} / V_{3}$ and, following same steps when proving (6), one obtain $\frac{x_{1,2}+x_{3}}{V_{1,2}+V_{3}}>\frac{x_{r}}{V_{r}}, r=\overline{4, n}$, that is $\frac{x_{1}+x_{2}+x_{3}}{V_{1}+V_{2}+V_{3}}>\frac{x_{r}}{V_{r}}, r=\overline{4, n}$. The same way it is easy to show that take place $\frac{x_{i}+x_{j}+x_{k}}{V_{i}+V_{j}+V_{k}}>\frac{x_{r}}{V_{r}}, i=\overline{1, r-3}, j=\overline{\imath+1, r-2}, k=\overline{\jmath+1, r-1}, r=\overline{4, n}$; and so on it $\operatorname{occur}(12) . v$

Now, similarly to reasoning when proving relation (6), because of $\frac{x_{1}}{V_{1}}>\frac{x_{2}}{V_{2}}$, for it to take place (7), it is sufficient to show that

$$
\frac{x_{2}}{V_{2}}>\frac{x_{2}+x_{3}}{V_{2}+V_{3}} .
$$

Let's consider the equality

$$
\frac{x_{2}}{V_{2}}=\frac{z+x_{3}}{V_{2}+V_{3}}
$$

From (14) one has $z=\left(x_{2} V_{2}+x_{2} V_{3}-x_{3} V_{2}\right) / V_{2}=x_{2} V_{3} / V_{2}+x_{2}-x_{3}$. If $x_{2}<z$ then, based on (13), (14) and $\frac{x_{1}}{V_{1}}>\frac{x_{2}}{V_{2}}$, the inequality (13) occurs, too. So, if takes place $x_{2}<x_{2} V_{3} / V_{2}+x_{2}-x_{3}$, that is if $x_{3} / V_{3}<x_{2} / V_{2}$, then the inequality (13) occurs. But the inequality $x_{3} / V_{3}<x_{2} / V_{2}$ takes place, then (13) occurs and therefore relation (7) occurs, too.

Similarly to considerations when obtaining (12), it is easy to show that occurs

$$
\frac{x_{j}}{V_{j}}>\frac{\sum_{i \in S} x_{i}}{\sum_{i \in S} V_{i}}
$$

where $j=\overline{1, n-1}$ and $S$ is any subset of $\{j+1,2, \ldots, n\}$. Indeed, noting $x_{2,3}=x_{2}+x_{3}$ and $V_{2,3}=$ $V_{2}+V_{3}$, based on (7) one has $x_{1} / V_{1}>x_{2,3} / V_{2,3}$ and, following same steps when proving (7) and (12), one obtain $\frac{x_{r}}{V_{r}}>\frac{x_{i, j}+x_{k}}{V_{i, j}+V_{k}}$, that is $\frac{x_{r}}{V_{r}}>\frac{x_{i}+x_{j}+x_{k}}{V_{i}+V_{j}+V_{k}} r=\overline{1, n-3}, i=\overline{r+1, n-2}, j=$ $\overline{l+1, r-1}, k=\overline{\jmath+1, r}$ and so on it occur (15). $v$

Finally, with refer to relation (8), based on (9) and (13) one has $\frac{x_{1}+x_{2}}{V_{1}+V_{2}}>\frac{x_{2}}{V_{2}}>\frac{x_{2}+x_{3}}{V_{2}+V_{3}}$, that is, $\frac{x_{1}+x_{2}}{V_{1}+V_{2}}>\frac{x_{2}+x_{3}}{V_{2}+V_{3}}$. In the same way, one has $\frac{x_{2}+x_{3}}{V_{2}+V_{3}}>\frac{x_{3}+x_{4}}{V_{3}+V_{4}}$. So, take place $\frac{x_{1}+x_{2}}{V_{1}+V_{2}}>\frac{x_{2}+x_{3}}{V_{2}+V_{3}}>$ $\frac{x_{3}+x_{4}}{V_{3}+V_{4}}$, that is, relation (8) occurs. Generalizing, based on same considerations, occur

$$
\frac{x_{i}+x_{j}}{V_{i}+V_{j}}>\frac{x_{r}+x_{k}}{V_{r}+V_{k}}, i=\overline{1, n-3}, j=\overline{\imath+1, n-2}, r=\overline{\jmath+1, n-1}, k=\overline{r+1, n} .
$$

Also, based on (4) and (15) one has $x_{1,2} / V_{1,2}>x_{3} / V_{3}>\left(x_{4}+x_{5}\right) /\left(V_{4}+V_{5}\right)$ and taking into account (16) occurs $\frac{x_{1,2}+x_{3}}{V_{1,2}+V_{3}}>\frac{x_{4}+x_{5}}{V_{4}+V_{5}}$, that is $\frac{x_{1}+x_{2}+x_{3}}{V_{1}+V_{2}+V_{3}}>\frac{x_{4}+x_{5}}{V_{4}+V_{5}}$. Similarly it is easy to show that relation $\frac{x_{1}+x_{2}}{V_{1}+V_{2}}>\frac{x_{3}+x_{4}+x_{5}}{V_{3}+V_{4}+V_{5}}$ takes place. Generalizing, based on same considerations and also taking into account relations (12) and (15), occur

$$
\frac{\sum_{i \in L} x_{i}}{\sum_{i \in L} V_{i}}>\frac{\sum_{j \in S} x_{j}}{\sum_{j \in S} V_{j}}
$$

where $L$ is any subset of $\{1,2, \ldots, r\}$ and $S$ is any subset of $\{r+1,2, \ldots, n\}$. Relations (17) are equivalent to the (1) ones for the case of $x_{1}>x_{2}>x_{3}>\ldots>x_{n}$. $\nabla$ 
Similarly as proving the sufficiency of conditions (4) compliance with all $K_{n}$ inequalities (17), that is with the (1) ones, can be proved the sufficiency of conditions (5) compliance with all $K_{n}$ inequalities (18)

$$
\frac{\sum_{i \in L} x_{i}}{\sum_{i \in L} V_{i}}<\frac{\sum_{j \in S} x_{j}}{\sum_{j \in S} V_{j}}
$$

where $L$ is any subset of $\{1,2, \ldots, r\}$ and $S$ is any subset of $\{r+1,2, \ldots, n\}$, that is with the (2) ones for the case of $x_{1}>x_{2}>x_{3}>\ldots>x_{n}$.

Based on Statement 2, can be simpler redefined the Definition 2 regarding the total favoring of large/small beneficiaries in an apportionment.

Definition 3. In an apportionment, large beneficiaries are totally favored if

$$
\frac{x_{i}}{V_{i}}>\frac{x_{j}}{V_{j}}
$$

and small beneficiaries are totally favored if

$$
\frac{x_{i}}{V_{i}}<\frac{x_{j}}{V_{j}}
$$

whenever $x_{i}>x_{j}$, where $i$ and $j$ take values from the $\{1,2,3, \ldots, n\}$ ones.

Based on Definition 3, can be defined the total favoring of large or of small beneficiaries by an apportionment method overall, on an infinity of apportionments. Evidently, the probability $p_{\mathrm{L}}$ of total favoring of large beneficiaries in an apportionment is determined as

$$
p_{\mathrm{L}}=\lim _{N \rightarrow \infty} \frac{N_{\mathrm{L}}}{N}
$$

where $N$ is the total number of apportionments, and $N_{\mathrm{L}}$ is the number of apportionments compliant with requirements (19). Similarly, the probability $p_{\mathrm{s}}$ of total favoring of small beneficiaries in an apportionment is determined as

$$
p_{\mathrm{S}}=\lim _{N \rightarrow \infty} \frac{N_{\mathrm{S}}}{N}
$$

where $N_{S}$ is the number of apportionments compliant with requirements (20). At the same time, indicator $p_{\mathrm{L}}$ alone does not determine the total favoring of large beneficiaries by apportionment methods, just as indicator $p_{\mathrm{S}}$ alone does not determine the total favoring of small beneficiaries by apportionment methods. It is well known that, in a particular apportionment, used methods can favor both some large and some small beneficiaries. This is why, when talking about the total favoring of beneficiaries by apportionment methods, it is needed to take into account both indicators: $p_{\mathrm{L}}$ and $p_{\mathrm{S}}$.

Definition 4. An apportionment method totally favors large beneficiaries if $p_{\mathrm{L}}>p_{\mathrm{S}}$, totally favors small beneficiaries if $p_{\mathrm{L}}<p_{\mathrm{S}}$ and it is neutral if $p_{\mathrm{L}}=p_{\mathrm{S}}$.

Definition 5. The grade of an apportionment method total favoring of large beneficiaries can be determined as $f_{\mathrm{L}}=p_{\mathrm{L}}-p_{\mathrm{S}}$ and that of total favoring of small beneficiaries - as $f_{\mathrm{S}}=p_{\mathrm{S}}-p_{\mathrm{L}}$. 


\section{Total favoring the beneficiaries by apportionment methods}

Evidently, the compliance with requirements (19), or the (20) ones, for all $n$ beneficiaries of an apportionment, especially when $n$ is large, is rare. For example, it is sufficient only in one of the $n-1$ cases to take place $V_{j}<V_{i} x_{j} / x_{i}$ and requirements (19) are not compliant. To determine, by computer simulation, the apportionment methods total favoring of large or of small beneficiaries, in sense of Definitions 4 and 5 , the SIMAP application has been elaborated and respective calculations have been made. The initial data used in calculations are: $M=6,11,21,51,101,201,501 ; n=2,3,4,5,7,10,15 ; n \leqslant M$ - $1 ; V=10^{8}$; uniform distribution of values $V_{i}, i=1, n$; sample size $N=10^{6}$. So, one has 45 variants of values for the pair $\{M, n\}: 4+6+7 \times 5=45$.

Although $N=10^{6}$, and not $\infty$, the $P_{\mathrm{L}} \approx 100 p_{\mathrm{L}}, P_{\mathrm{S}} \approx 100 p_{\mathrm{S}}, F_{\mathrm{L}} \approx 100 f_{\mathrm{L}}$ and $F_{\mathrm{S}} \approx 100 f_{\mathrm{S}}$ notations will be used. The values of frequencies $P_{\mathrm{L}}, P_{\mathrm{S}}, F_{\mathrm{L}}$ and $F_{\mathrm{S}}$ are measured in percentages. So, for example:

- $P_{\mathrm{L}}(\mathrm{H})$ is the percentage of apportionments, in which large beneficiaries are totally favored, when applying the Hamilton method;

- $P_{\mathrm{s}}(\mathrm{HH})$ is the percentage of apportionments, in which small beneficiaries are totally favored, when applying the Huntington-Hill method;

- $F_{\mathrm{L}}\left(\mathrm{d}^{\prime} \mathrm{H}\right)$ is the percentage of total favoring of large beneficiaries by d'Hondt method, that is the difference between the percentage of apportionments, in which large beneficiaries are totally favored and the one, in which small beneficiaries are totally favored, when applying the d'Hondt method.

Here, it is necessary to mention that, although the Hamilton $(H)$ and Sainte-Laguë (SL) methods are neutral in terms of favoring the beneficiaries [6], that is $F_{\mathrm{L}}(\mathrm{H})=F_{\mathrm{S}}(\mathrm{H})=$ $F_{\mathrm{L}}(\mathrm{SL})=F_{\mathrm{S}}(\mathrm{SL})=0$, there may still be apportionments, in which large beneficiaries are totally favored, or ones, in which small beneficiaries are totally favored, even applying these methods, but take place $P_{\mathrm{L}}(\mathrm{H})=P_{\mathrm{S}}(\mathrm{H})$ and $P_{\mathrm{L}}(\mathrm{SL})=P_{\mathrm{S}}(\mathrm{SL})$. Also, for all apportionment methods at $n=2$ and $x_{1} N_{1} \neq x_{2} N_{2}$, the equality $P_{\mathrm{L}}+P_{\mathrm{S}}=100 \%$ takes place.

\subsection{Total favoring of beneficiaries by Hamilton method}

Because of $P_{\mathrm{L}}(\mathrm{H})=P_{\mathrm{S}}(\mathrm{H})$, only the percentage of apportionments, in which large beneficiaries are totally favored is examined. The graphs of $P_{\mathrm{L}}(\mathrm{H})$ indicators dependence to $M$ and $n$, when using Hamilton method, are shown in Figure 1. One can see that $P_{\mathrm{L}}(\mathrm{H})$ little depends on $M$, but is strongly decreasing to $n$. For $11 \leqslant M \leqslant 501$, the $P_{\mathrm{L}}(\mathrm{H})$ value (Figure 1 and the results of calculations) belong to the range [17.5\%; 18.3\%] at $n=3$, to the range [3.7\%; $5.1 \%]$ at $n=4$, to the range $[0.6 \% ; 1.2 \%]$ at $n=5$ and is very close to $0 \%$ at $n \geqslant 7$. So, along with $n=2$, many cases of apportionments with totally favored large (small) beneficiaries are only at $n=3(17.5 \div 18.3 \%)$ and no so many at $n=4(3.7 \div 5.1 \%)$.

\subsection{Total favoring of beneficiaries by Sainte-Laguë method}

Because of $P_{\mathrm{L}}(\mathrm{SL})=P_{\mathrm{S}}(\mathrm{SL})$, only the percentage of apportionments, in which large beneficiaries are totally favored, is examined. The graphs of $P_{\mathrm{L}}(\mathrm{SL})$ indicators dependence to $M$ and $n$, when using Sainte-Laguë method, are shown in Figures 2. One can see that $P_{\mathrm{L}}(\mathrm{SL})$ little depends on $M$, but it is strongly decreasing to $n$. For $11 \leqslant M \leqslant 501$, the $P_{\mathrm{L}}(\mathrm{H})$ value (Figure 2 and the results of calculations) belong to the range [19.1\%; 19.5\%] at $n=3$, to the range [5.0\%; 6.3\%] at $n=4$, to the range [1.1\%; $1.8 \%]$ at $n=5$ and is very close to $0 \%$ at $n \geqslant 7$. 


\subsection{Total favoring of beneficiaries by d'Hondt method}

The graphs of $P_{\mathrm{L}}\left(\mathrm{d}^{\prime} \mathrm{H}\right), P_{\mathrm{S}}\left(\mathrm{d}^{\prime} \mathrm{H}\right)$ and $F_{\mathrm{L}}\left(\mathrm{d}^{\prime} \mathrm{H}\right)$ indicators dependence to $M$ and $n$, when using d'Hondt method, are shown in Figures 3, 4 and 5, respectively. In all of them, less the case of $M=6$, the value of $P_{\mathrm{L}}\left(\mathrm{d}^{\prime} \mathrm{H}\right), P_{\mathrm{S}}\left(\mathrm{d}^{\prime} \mathrm{H}\right)$ and $F_{\mathrm{L}}\left(\mathrm{d}^{\prime} \mathrm{H}\right)$ indicators little depends on $M$, but is strongly decreasing to $n$. In more detail, however, for $11 \leqslant M \leqslant 501$, the on $M$ dependence:

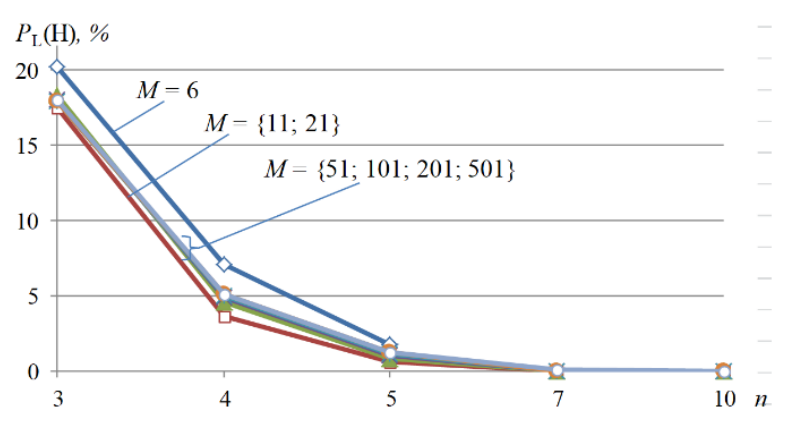

Figure 1. The $n$ dependence of the percentage of Hamilton method apportionments, in which the large beneficiaries are favored.

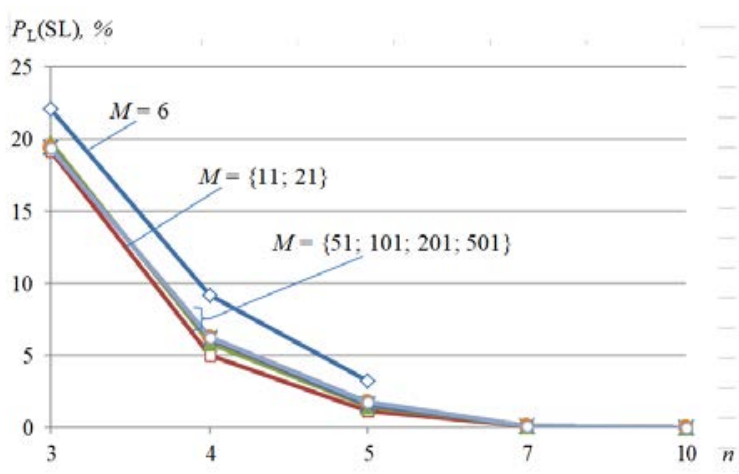

Figure 2. The $n$ dependence of the percentage of Sainte-League method apportionments, in which the large beneficiaries are favored.

- of $P_{\mathrm{L}}\left(\mathrm{d}^{\prime} \mathrm{H}\right)$ and $F_{\mathrm{L}}\left(\mathrm{d}^{\prime} \mathrm{H}\right)$ values is decreasing at $n=2$ and is increasing at $n \geqslant 3$;

- of $P_{\mathrm{s}}\left(\mathrm{d}^{\prime} \mathrm{H}\right)$ value, on contrary, is increasing at $n=2$ and is decreasing at $n \geqslant 3$ (except the interval of $M=11 \div 21$ at $n=3$, which is increasing);

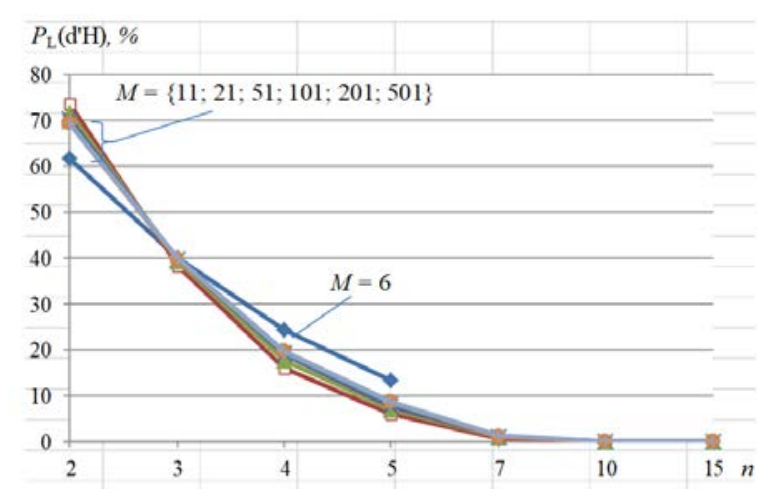

Figure 3. The $n$ dependence of the percentage of d'Hondt method apportionments, in which the large beneficiaries are favored.

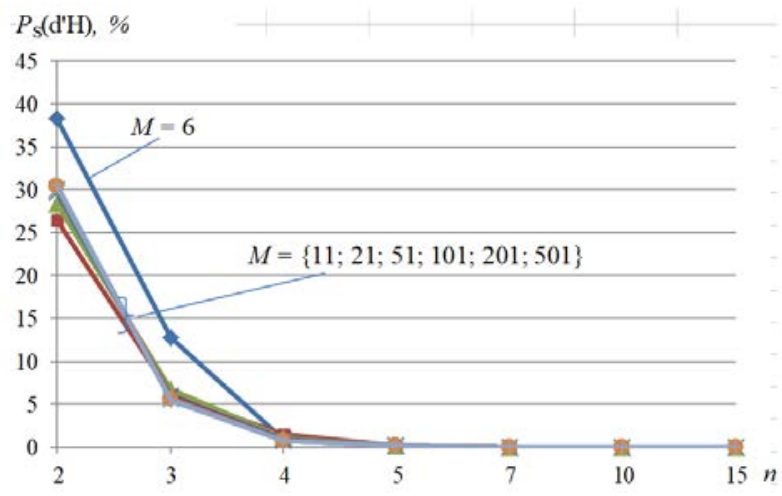

Figure 4. The $n$ dependence of the percentage of d'Hondt method apportionments, in which the small beneficiaries are favored.

Thus, for $11 \leqslant M \leqslant 501$, the $P_{L}\left(d^{\prime} H\right)$ value (Figure 3 and the results of calculations) belong to the range [69.3\%; 73.6\%] at $n=2$, to the range [38.4\%; 39.9\%] at $n=3$, to the range $[16.1 \% ; 19.7 \%]$ at $n=4$, to the range $[5.9 \% ; 8.6 \%]$ at $n=5$, to the range $[0.7 \% ; 1.2 \%]$ at $n=7$ and is very close to $0 \%$ at $n \geqslant 10$.

For $11 \leqslant M \leqslant 501$, the $P_{s}\left(d^{\prime} H\right)$ value (Figure 4 and the results of calculations) belong to the range $[26.4 \% ; 30.7 \%]$ at $n=2$, to the range $[5.5 \% ; 6.7 \%]$ at $n=3$, to the range $[0.7 \%$; $1.5 \%]$ at $n=4$, to the range [0.1\%; $0.2 \%]$ at $n=5$ and is very close to $0 \%$ at $n \geqslant 7$. Also, by comparing data of Figures 3 and 4, one can see that in all examined cases it takes place $P_{\mathrm{L}}\left(\mathrm{d}^{\prime} \mathrm{H}\right)>P_{\mathrm{S}}\left(\mathrm{d}^{\prime} \mathrm{H}\right)$. 
Similarly, for $11 \leqslant M \leqslant 501$, the $F_{\mathrm{L}}\left(\mathrm{d}^{\prime} \mathrm{H}\right)$ value (Figure 5 and the results of calculations) belong to the range [38.6\%; 47.3\%] at $n=2$, to the range [32.1\%; 34.4\%] at $n=3$, to the range [14.6\%; 19.0\%] at $n=4$, to the range [5.7\%; 8.5\%] at $n=5$, to the range $[0.6 \% ; 1.2 \%$ ] at $n=7$ and is very close to $0 \%$ at $n \geqslant 10$. Thus, Figure 5 clearly show that on average the d'Hondt method totally favors large beneficiaries, the percentage of total favoring being considerable at small values of $n$, especially at $n \leqslant 5$ beneficiaries.

\subsection{Total favoring of beneficiaries by Huntington-Hill method}

The graphs of $P_{\mathrm{S}}(\mathrm{HH}), P_{\mathrm{L}}(\mathrm{HH})$ and $F_{\mathrm{S}}(\mathrm{HH})$ indicators dependence to $M$ and $n$, when using Huntington-Hill method, are shown in Figures 6, 7 and 8, respectively.

According to Figures 6 and 7, the on $M$ dependence of the $P_{\mathrm{L}}(\mathrm{HH})$ indicator is decreasing and of the $P_{\mathrm{s}}(\mathrm{HH})$ indicator is increasing, but the on $n$ dependence are both strongly decreasing. So, for $11 \leqslant M \leqslant 501$, the $P_{\mathrm{S}}(\mathrm{HH})$ value (Figure 6 and the results of calculations) belong to the range [50.2\%; 53.2\%] at $n=2$, to the range [24.2\%; $40.2 \%]$ at $n=$ 3 , to the range [10.5\%; 28.7\%] at $n=4$, to the range [4.1\%; 20.5\%] at $n=5$, to the range [0.4\%; $13.2 \%$ ] at $n=7$, to the range [0.0\%; 2.6\%] at $n=10$, is equal to $0.6 \%$ at $M=21, n=10$ and is very close to $0 \%$ at $\{51 \leqslant M \leqslant 501, n \geqslant 10\}$. For $11 \leqslant M \leqslant 501$, the $P_{\mathrm{L}}(\mathrm{HH}$ ) value (Figure 7 and the results of calculations) belong to the range [46.8\%; 49.8\%] at $n=2$, to the range [10.7\%; 23.1\%] at $n=3$, to the range [1.1\%; 9.6\%] at $n=4$, to the range $[0.0 \% ; 3.5 \%$ ] at $n=$ 5 , to the range $[0.0 \% ; 0.3 \%]$ at $n=7$ and is very close to $0 \%$ at $n \geqslant 10$.

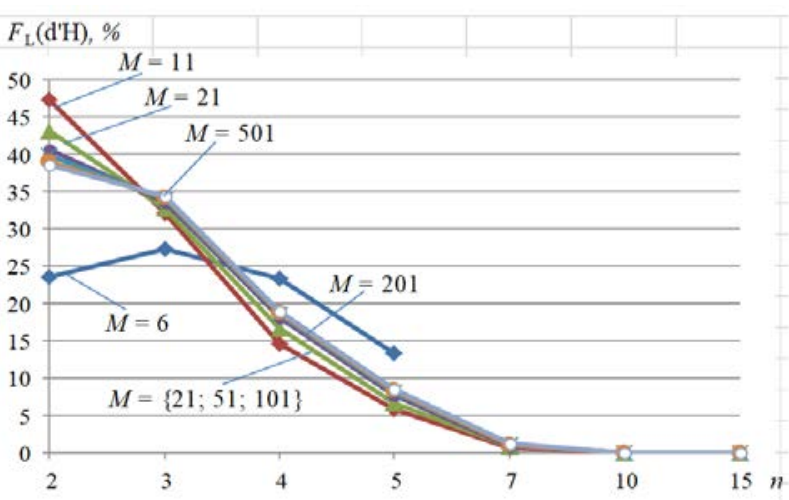

Figure 5. The $n$ dependence of the d'Hondt method total favoring of large beneficiaries in apportionments.

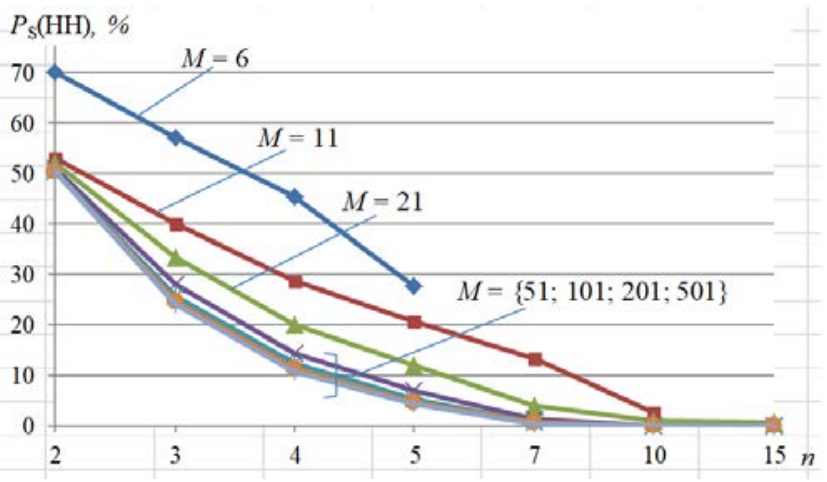

Figure 6. The $n$ dependence of the percentage of Huntington-Hill method apportionments, in which the small beneficiaries are favored.

An another situation is regarding the graphs of $F_{\mathrm{S}}(\mathrm{HH})$ indicator dependence to $M$ and $n$, when using the Huntington-Hill method.

According to Figure 8, the on $M$ dependence of the $F_{\mathrm{s}}(\mathrm{HH})$ is decreasing, but the on $n$ dependence of it is increasing in the range from $n=2$ to $n=3$ and is decreasing for $n \geqslant 3$.

So, for $11 \leqslant M \leqslant 501$, the $F_{\mathrm{L}}(\mathrm{HH})$ value (Figure 8 and the results of calculations) belong to the range $[0.5 \% ; 6.4 \%]$ at $n=2$, to the range [1.0\%; 29.4\%] at $n=3$, to the range [1.0\%; 27.6\%] at $n=4$, to the range $[0.6 \% ; 20.5 \%]$ at $n=5$, to the range $[0.1 \% ; 13.2 \%]$ at $n=$ 7 ; it is equal to 2,6 at $\{M=11, n=10\}$, to $0.9 \%$ at $\{M=21, n=10\}$, to $0.6 \%$ at $\{M=21, n=$ $15\}$ and is very close to $0 \%$ at $\{51 \leqslant M \leqslant 501, n \geqslant 10\}$. 
Thus, Figure 8 clearly show that on average the Huntington-Hill method totally favors small beneficiaries, the percentage of total favoring being considerable at small values of $n$, especially at $3 \leqslant n \leqslant 5$.

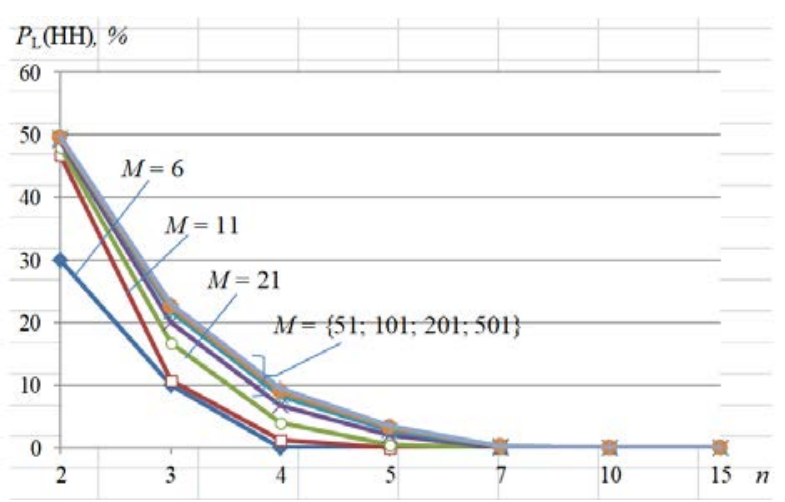

Figure 7. The $n$ dependence of the percentage of Huntington-Hill method apportionments, in which the large beneficiaries are favored.

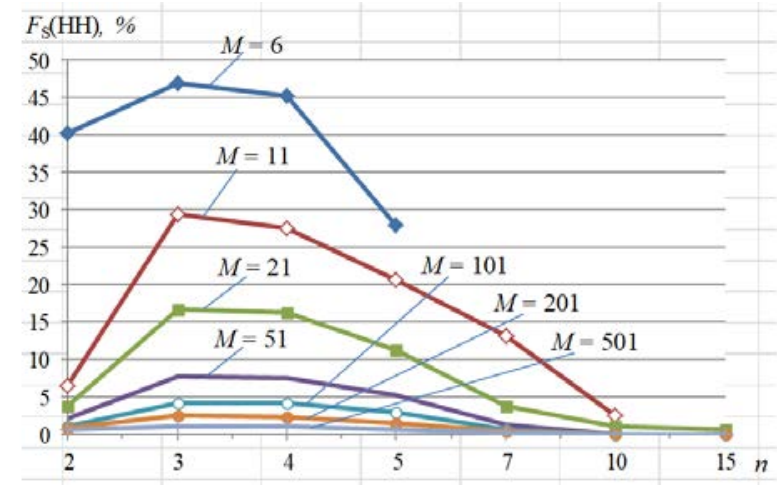

Figure 8. The $n$ dependence of the Huntington-Hill method total favoring of small beneficiaries in apportionments.

\subsection{Total favoring of beneficiaries by Adapted Sainte-Laguë method}

The graphs of $F_{\mathrm{S}}(\mathrm{ASL})$ indicator dependence to $M$ and $n$, when using Adapted SainteLaguë (ASL) method, are shown in Figure 9. If to not take into account the case of $M=6$, the on $M$ dependence of $F_{\mathrm{s}}(\mathrm{HH})$ is decreasing, but the on $n$ dependence of it is increasing in the range from $n=2$ to $n=3$ and is decreasing for $n \geqslant 3$.

So, for $11 \leqslant M \leqslant 501$, the $F_{\mathrm{L}}\left(\mathrm{d}^{\prime} \mathrm{H}\right)$ value (Figure 9 and the results of calculations) belong to the range $[0.3 \% ; 16.3 \%]$ at $n=3$, to the range $[0.3 \% ; 12.5 \%]$ at $n=4$, to the range $[0.2 \% ; 8.9 \%]$ at $n=5$, to the

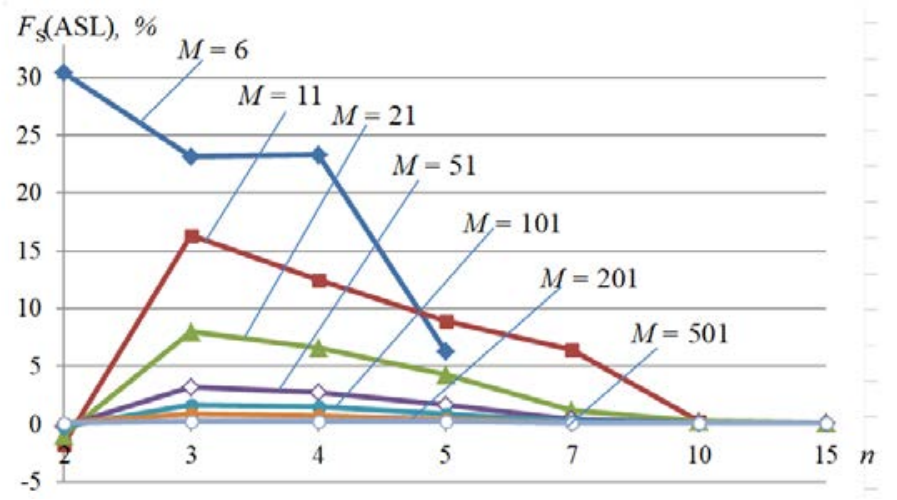

Figure 9. The $n$ dependence of the Adapted SainteLaguë method total favoring of small beneficiaries in apportionments. range $[0.0 \% ; 6.4 \%]$ at $n=7$; it is equal to 0,2 at $\{M=11, n=10\}$, to $0.3 \%$ at $\{M=21, n=10\}$, to $0.1 \%$ at $\{M=21, n=15\}$ and is very close to $0 \%$ at $\{51 \leqslant M \leqslant 501, n \geqslant 10\}$.

\section{Comparative analyses of apportionment methods}

As expected, for all examined APP methods, the on $n$ dependence of $P_{\mathrm{L}}(\cdot)$ and $P_{\mathrm{S}}(\cdot)$ indicators are strongly decreasing (see Figures $1-4,6$ and 7), while those of $F_{\mathrm{L}}\left(\mathrm{d}^{\prime} \mathrm{H}\right)$ and $F_{\mathrm{S}}(\mathrm{HH})$ and $F_{\mathrm{S}}(\mathrm{ASL})$ (see Figures 5, 8 and 9) are different - they are increasing for some segments and decreasing for the others. Comparing Figures 1 and 2, one can see the strong similarity of the character of dependences on $M$ and $n$ of indicators $P_{\mathrm{L}}(\mathrm{H})$ and $P_{\mathrm{L}}(\mathrm{SL})$.

Also, the results of calculations show that occur relations:

1) $P_{\mathrm{L}}(\mathrm{H})=P_{\mathrm{S}}(\mathrm{H})<P_{\mathrm{L}}(\mathrm{SL})=P_{\mathrm{S}}(\mathrm{SL})$;

2) $P_{\mathrm{L}}\left(\mathrm{d}^{\prime} \mathrm{H}\right)>\max \left\{P_{\mathrm{S}}\left(\mathrm{d}^{\prime} \mathrm{H}\right), P_{\mathrm{L}}(\mathrm{H}), P_{\mathrm{S}}(\mathrm{H}), P_{\mathrm{L}}(\mathrm{SL}), P_{\mathrm{S}}(\mathrm{SL}), P_{\mathrm{L}}(\mathrm{ASL}), P_{\mathrm{L}}(\mathrm{HH})\right\}$;

3) $P_{\mathrm{S}}(\mathrm{HH})>\max \left\{P_{\mathrm{S}}\left(\mathrm{d}^{\prime} \mathrm{H}\right), P_{\mathrm{L}}(\mathrm{H}), P_{\mathrm{S}}(\mathrm{H}), P_{\mathrm{L}}(\mathrm{SL}), P_{\mathrm{S}}(\mathrm{SL}), P_{\mathrm{S}}(\mathrm{ASL}), P_{\mathrm{L}}(\mathrm{ASL}), P_{\mathrm{L}}(\mathrm{HH})\right\}$; 
4) $P_{\mathrm{S}}(\mathrm{HH})<P_{\mathrm{S}}(\mathrm{ASL})$, at $n=2$ and, also, at $\{M=[6 \div 11] ; n=3\}$;

5) $P_{\mathrm{s}}(\mathrm{HH})>P_{\mathrm{s}}(\mathrm{ASL})$, at $n=\geqslant 4$.

Of course, relations among $F_{\mathrm{L}}\left(\mathrm{d}^{\prime} \mathrm{H}\right), F_{\mathrm{S}}(\mathrm{HH})$ and $F_{\mathrm{S}}(\mathrm{ASL})$ indicators are the most important. The on $M$ and $n$ dependence of differences $F_{\mathrm{L}}\left(\mathrm{d}^{\prime} \mathrm{H}\right)-F_{\mathrm{S}}(\mathrm{HH}), F_{\mathrm{L}}\left(\mathrm{d}^{\prime} \mathrm{H}\right)-F_{\mathrm{S}}(\mathrm{ASL})$ and $F_{S}(\mathrm{HH})-F_{S}(\mathrm{ASL})$ are shown in Figures 10, 11 and 12, respectively.

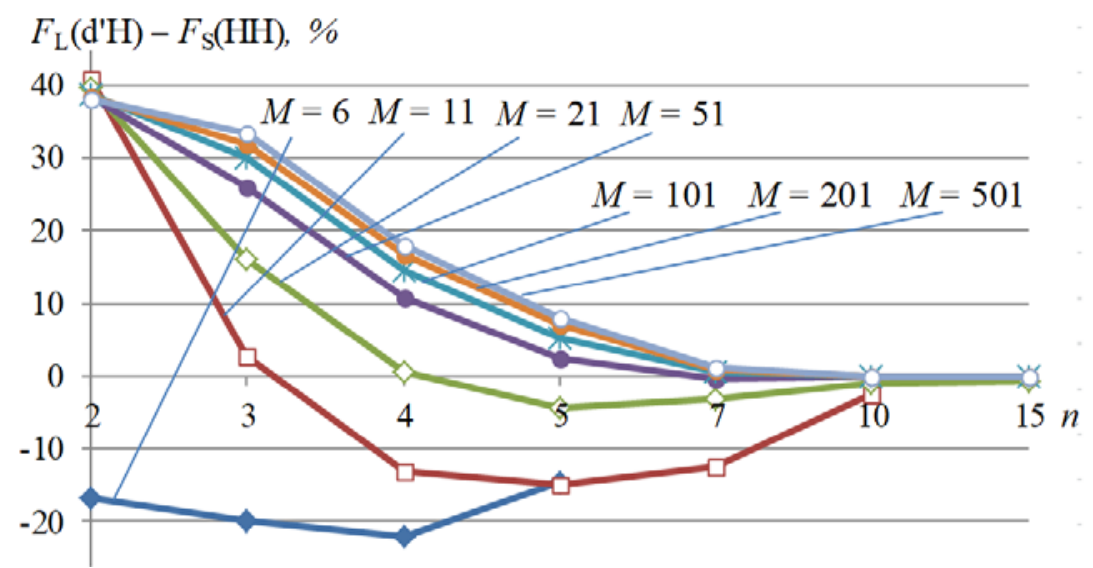

Figure 10. The difference $F_{L}\left(d^{\prime} H\right)-F_{S}(H H)$ dependence to $n$.

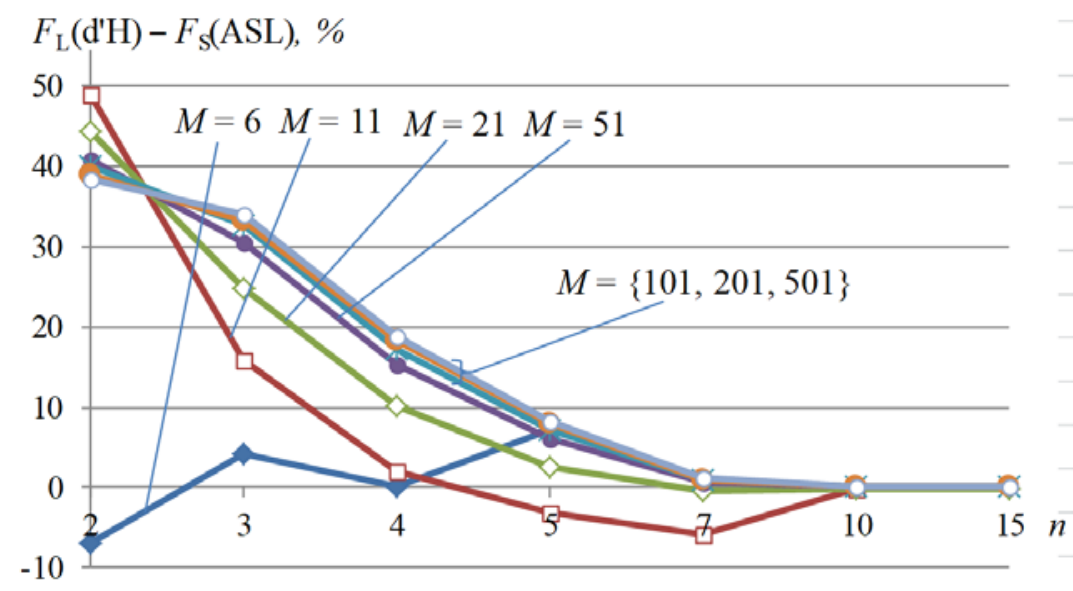

Figure 11. The difference $\mathrm{F}_{\mathrm{L}}\left(\mathrm{d}^{\prime} \mathrm{H}\right)-\mathrm{F}_{\mathrm{S}}(\mathrm{ASL})$ dependence to $n$.

Although it is considered that d'Hondt method favors large beneficiaries strongly, and Huntington-Hill method favors small beneficiaries slightly, with refer to total favoring of beneficiaries, in many cases relation $F_{\mathrm{L}}\left(\mathrm{d}^{\prime} \mathrm{H}\right)<$ $F_{\mathrm{S}}(\mathrm{HH})$ occur (Figure 10), especially at small values of $M$. Moreover, there are cases when relation $F_{\mathrm{L}}\left(\mathrm{d}^{\prime} \mathrm{H}\right)<$ $F_{\mathrm{S}}(\mathrm{ASL})$ takes place, too (Figure 11).

However, mostly, relations $F_{\mathrm{L}}\left(\mathrm{d}^{\prime} \mathrm{H}\right)>F_{\mathrm{S}}(\mathrm{HH})$ and $F_{\mathrm{L}}\left(\mathrm{d}^{\prime} \mathrm{H}\right)>F_{\mathrm{S}}(\mathrm{ASL})$ occur. At the same time, there are

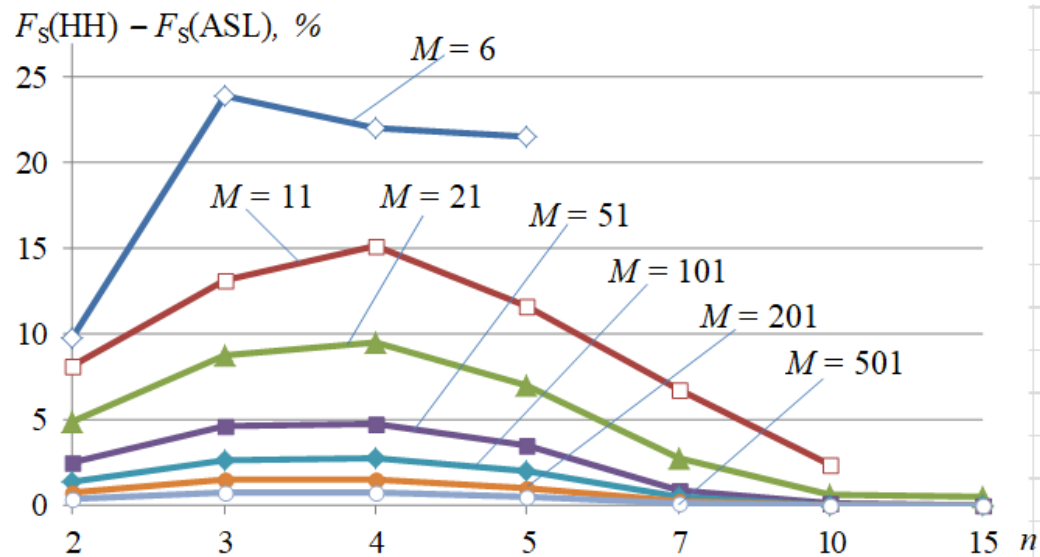

Figure 12. The difference $\mathrm{F}_{\mathrm{S}}(\mathrm{HH})-\mathrm{F}_{\mathrm{S}}(\mathrm{ASL})$ dependence to $n$. 
no alternatives for the difference $F_{S}(H H)-F_{S}(A S L)$ - it is always positive, that is $F_{S}(H H)>$ $F_{S}(A S L)$ (see Figure 12). Thus, Adapted Sainte-Laguë method rarer, than the Huntington-Hill one, implies the total favoring of beneficiaries - of the small ones.

\section{Conclusions}

The conditions of favoring large or small beneficiaries (parties) by an apportionment method defined in [1] (Definition 2) are very strong. There are no known such methods that would be used in practice. But these conditions can be used to identify the favoring of large or of small beneficiaries in particular apportionments. At the same time, in one and the same apportionment may be favored some large beneficiaries and some small ones and, however, predominantly to be favored large or, on the contrary, small beneficiaries. Therefore it is proposed to use two different notions: "favoring" of large or of small beneficiaries and "total favoring" of large or of small beneficiaries, the second one being a particular case of the first. The compliance of an apportionment with conditions (1) or with the (2) ones is referred to "total favoring" of large or, respectively, of small beneficiaries. The larger notion of favoring of large or of small beneficiaries is used when in an apportionment are predominantly favored large or, on the contrary, small beneficiaries in sense of [8].

There has been obtained the formula for determining the number $K_{n}$ of conditions (1) or (2) for computer simulation. But this number is growing very fast with the growth of the number $n$ of beneficiaries, exceeding 2 mil at $n=20$. Fortunately, it was possible to overcome this situation. Thus, the volume of needed calculus for computer simulation was considerably reduced.

In order to estimate quantitatively the total favoring of beneficiaries, three indicators were used: (a) the percentage $P_{\mathrm{L}}(\cdot)$ of apportionments, in which large beneficiaries are totally favored; (b) the percentage $P_{\mathrm{s}}(\cdot)$ of apportionments, in which small beneficiaries are totally favored; (c) the percentage of total favoring of large $F_{\mathrm{L}}(\cdot)$ or of small $F_{\mathrm{S}}(\cdot)$ beneficiaries, depending on the APP method applied. A total of five APP methods are being researched: Hamilton, Sainte-Laguë, d'Hondt, Huntington-Hill and Adapted Sainte-Laguë. The initial data used in calculations are: $M=6,11,21,51,101,201,501 ; n=2,3,4,5,7,10$, $15 ; n \leqslant M-1 ; V=10^{8}$; uniform distribution of values $V_{i}, i=\overline{1, n}$; sample size $N=10^{6}$.

As expected, for all five methods the on $n$ dependence of indicators $P_{\mathrm{L}}(\cdot)$ and $P_{\mathrm{S}}(\cdot)$ is strongly decreasing, becoming approx. 0 at $n \geqslant 7 \div 10$. With refer to the on $n$ dependence of indicators $F_{\mathrm{L}}\left(\mathrm{d}^{\prime} \mathrm{H}\right), F_{\mathrm{S}}(\mathrm{HH})$ and $F_{\mathrm{S}}(\mathrm{ASL})$ it is increasing for some of $n=2 \div 3$ segments and is decreasing for the others.

Also, take place the relations:

1) $P_{\mathrm{L}}(\mathrm{H})=P_{\mathrm{S}}(\mathrm{H})<P_{\mathrm{L}}(\mathrm{SL})=P_{\mathrm{S}}(\mathrm{SL})$;

2) $P_{\mathrm{L}}\left(\mathrm{d}^{\prime} \mathrm{H}\right)>\max \left\{P_{\mathrm{S}}\left(\mathrm{d}^{\prime} \mathrm{H}\right), P_{\mathrm{L}}(\mathrm{H}), P_{\mathrm{S}}(\mathrm{H}), P_{\mathrm{L}}(\mathrm{SL}), P_{\mathrm{S}}(\mathrm{SL}), P_{\mathrm{L}}(\mathrm{ASL}), P_{\mathrm{L}}(\mathrm{HH})\right\}$;

3) $P_{\mathrm{S}}(\mathrm{HH})>\max \left\{P_{\mathrm{S}}\left(\mathrm{d}^{\prime} \mathrm{H}\right), P_{\mathrm{L}}(\mathrm{H}), P_{\mathrm{S}}(\mathrm{H}), P_{\mathrm{L}}(\mathrm{SL}), P_{\mathrm{S}}(\mathrm{SL}), P_{\mathrm{S}}(\mathrm{ASL}), P_{\mathrm{L}}(\mathrm{ASL}), P_{\mathrm{L}}(\mathrm{HH})\right\}$;

4) $P_{\mathrm{S}}(\mathrm{HH})<P_{\mathrm{S}}(\mathrm{ASL})$, at $n=2$ and, also, at $\{M=[6 \div 11] ; n=3\}$;

5) $P_{\mathrm{S}}(\mathrm{HH})>P_{\mathrm{S}}(\mathrm{ASL})$, at $n=\geqslant 4$.

At the same time, in many cases relation $F_{\mathrm{L}}\left(\mathrm{d}^{\prime} \mathrm{H}\right)<F_{\mathrm{S}}(\mathrm{HH})$ occurs, especially at small values of $M$, and in some cases relation $F_{\mathrm{L}}\left(\mathrm{d}^{\prime} \mathrm{H}\right)<F_{\mathrm{S}}(\mathrm{ASL})$ takes place. However, mostly, relations $F_{\mathrm{L}}\left(\mathrm{d}^{\prime} \mathrm{H}\right)>F_{\mathrm{S}}(\mathrm{HH})$ and $F_{\mathrm{L}}\left(\mathrm{d}^{\prime} \mathrm{H}\right)>F_{\mathrm{S}}(\mathrm{ASL})$ occur. So, not for all values of the pare $\{M, n\}$ Huntington-Hill and Adapted Sainte-Laguë method ensure less total favoring of small 
beneficiaries than d'Hondt method totally favors large beneficiaries. But always $F_{\mathrm{S}}(\mathrm{HH})>$ $F_{\mathrm{S}}(\mathrm{ASL})$, that is Adapted Sainte-Laguë method rarer, than the Huntington-Hill one, implies the total favoring of small beneficiaries.

\section{References}

1. Balinski M.L., Young H.P. Fair Representation: Meeting the Ideal of One Man, One Vote. 2nd ed. Washington, DC: Brookings Institution Press, 2001.

2. Kohler U., Zeh J. Apportionment methods. The Stata Journal, 2012, 12(3), pp. 375-392.

3. Niemeyer H.F., Niemeyer A.C. Apportionment Methods. Math. Social Sci., Vol. 56, Issue 2 (2008), pp. 240253. University of Western Australia, arXiv: 1510.07528v1 [math.HO], Oct. 27, 2015, pp. 1-24. (https://arxiv.org/pdf/1510.07528.pdf, accessed 25.07.2020).

4. Gallagher M. Proportionality, Disproportionality and Electoral Systems. Electoral Studies, 1991, 10(1), pp. 33-51.

5. Karpov A. Measurement of disproportionality in proportional representation. Mathematical and Computer Modeling, 2008, 48, pp. 1421-1438.

6. Bolun I. Favoring multioptional decisions. Mathematic modeling, optimization and information technologies. Proc. of int. sc. conf., March 22-25, 2016. Ed. 5, Vol. I. Chisinau: Evrica, ATIC, 2016. - pp. 35-45. [in Romanian]

7. Marshall A., Olkin I. \& Pukelsheim F. A majorization comparison of apportionment methods in proportional representation. Social Choice Welfare 19,885-900 (2002). (https://doi.org/10.1007/s003550200164, accessed 25.07.2020).

8. Bolun I. A criterion for estimating the favoring of beneficiaries in apportionments. Proceedings of Workshop on Intelligent Informatition Systems WIIS2020, December 04-05, 2020. Chisinau: IMI, 2020. - pp. 33-41.

9. Tannenbaum P. Excursions in Modern Mathematics, Seventh Edition. Pearson, 2008. - 704 p.

10. Sorescu A., Pirvulescu C. and al. Electoral systems. Bucharest: Pro Democratia, 2006. - 54 p. [in Romanian]. 